\section{A ERGOLOGIA COMO APORTE TEÓRICO -METODOLÓGICO PARA ANÁLISE COLETIVA DO TRABALHO DO BIBLIOTECÁRIO}

\author{
Ana Claudia Borges Campos* \\ Dulcinea Sarmento Rosemberg**
}

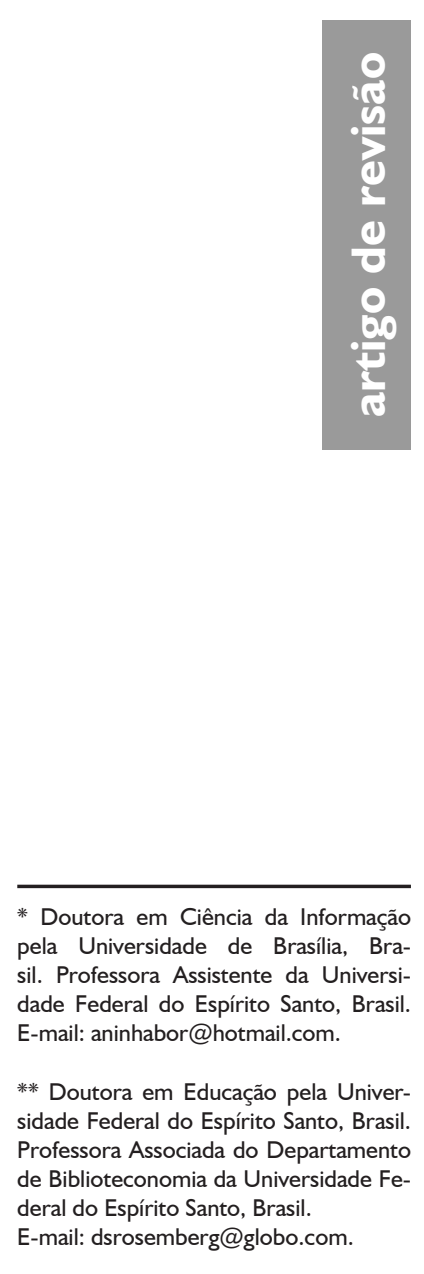

\begin{abstract}
Apresenta a Ergologia como aporte teórico-metodológico, idealizada por Yves Schwartz, para viabilizar a análise coletiva do trabalho do bibliotecário a partir de uma pesquisa que teve como objetivo principal colocar em análise a atividade de gestão de informação por bibliotecários-gestores. Discorre sobre a Ergologia como abordagem teórica potente para a análise coletiva do trabalho dispensando a hierarquização de saberes entre trabalhadores e pesquisadores. Ressalta o método ergológico como relevante dispositivo para disparar a análise das atividades laborais pelos próprios trabalhadores. Socializa o método ergológico que propiciou o processo dialógico equânime entre bibliotecários, alunos e docentes de Biblioteconomia sobre a atividade de gestão da informação. Conclui-se que a utilização do referido método para análise do trabalho instiga os trabalhadores a uma reflexividade sobre o seu trabalho, o que resulta na ampliação do poder de agir, no caso, dos bibliotecários que, historicamente, vêm sendo convocados a colocarem em questão: o que fazem? Como fazem? Por que fazem? Para que fazem?
\end{abstract}

Palavras-chave: Trabalho do bibliotecário. Ergologia. Análise da atividade de trabalho. Ergologia. Análise coletiva do trabalho.

\section{INTRODUÇÃO}

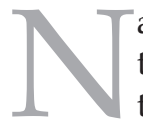
a era atual, os avanços em ciência e tecnologia, as mudanças no mundo do trabalho, as redefinições da economia mundial, bem como a falta de solução de antigos problemas sociais e a emergência de outros mais complexos, impõem aos profissionais das diferentes áreas do conhecimento a necessidade de refletirem e buscarem permanentemente uma interação sistemática e efetiva entre o mundo do trabalho, a formação e a atuação profissional.

Para Castells (2005) o Século XXI representa a "era da perplexidade consciente" onde o compromisso da Era da Informação concebe o desencadeamento de uma capacidade produtiva nunca antes apresentada, pautada no poder cognitivo para a produção de conhecimentos. Conhecimentos esses que geram inovação e constituem as bases da competitividade atual das organizações. Entretanto, uma grande defasagem entre nosso excesso de desenvolvimento tecnológico e o subdesenvolvimento social pode ser observada, especialmente quando se trata da formação educacional nos países emergentes (CASTELLS, 2005).

Segundo Sampaio (2005, p. 421) “[...] formação profissional e educação são peças chaves para as competências exigidas na nova economia da informação e do conhecimento [...]", sendo condição indispensável que a capacidade de aprendizado seja ampliada a todos os cidadãos em todos os domínios da vida social e profissional. Assim surgem novos formatos de competitividade baseados na formação dos trabalhadores, especialmente no que tange aos conhecimentos, habilidades e atitudes dirigidos ao desenvolvimento de quaisquer atividades laborais.

Em virtude desse panorama há décadas a produção técnico-científica em Biblioteconomia e 
Ciência da Informação vem prescrevendo para os bibliotecários, de modo sistemático e relevante, os conhecimentos que devem adquirir; as habilidades que devem desenvolver; e como devem agir no exercício das suas funções profissionais. Entretanto, acreditamos que além dessas contribuições torna-se cada vez mais urgente que os próprios bibliotecários coloquem em análise o seu trabalho, porém, não isoladamente. Pelo contrário, defendemos a ideia de que o processo dialógico entre docentes de Biblioteconomia e bibliotecários ao deflagrar uma reflexividade pode provocar o aumento do poder de agir dos trabalhadores em, no mínimo três dimensões, que se complementam, quais sejam: desenvolvimento de novas estratégias para enfrentamento dos ambientes laborais; apropriação de modos de fazer e de saberes em prol da competência profissional; e potencialização de ações dirigidas aos cuidados consigo e com o outro, na medida em que a atividade de trabalho sempre é dirigida a si, ao outro e à própria atividade (CLOT, 2011) .

Daí a aposta na abordagem teóricometodológica, idealizada por Yves Schwartz, por proporcionar a análise coletiva do trabalho na perspectiva enunciada, que tem como uma de suas características a não hierarquização entre trabalhadores e pesquisadores, o que significa aprender com o outro ao mesmo tempo em que emprestamos nosso saber para a construção do saber do outro (SCHWARTZ, 2000). Em suma, as questões que atingem o trabalho não devem ser abordadas somente pelo viés de pesquisadores ou apenas pelo olhar dos trabalhadores. Para Schwartz (2000) é necessário que ambos os sujeitos contribuam para a compreensão do trabalho.

Neste contexto, este trabalho objetiva discorrer sobre a Ergologia como abordagem teórica potente para a análise coletiva do trabalho; apresentar o método ergológico como relevante dispositivo para disparar análises das atividades laborais pelos próprios trabalhadores, socializando o método ergológico que propiciou o processo dialógico equânime entre bibliotecários, alunos e docentes de Biblioteconomia sobre a atividade de gestão da informação. ${ }^{1}$

\footnotetext{
Os resultados específicos sobre a análise ergológica da atividade de gestão da informação não serão objeto deste trabalho.
}

\section{A ERGOLOGIA COMO ABORDA- GEM TEÓRICO-METODOLÓGICA PARA ANÁLISE COLETIVA DO TRABALHO DE BIBLIOTECÁRIOS}

A abordagem Ergológica originou-se da Ergonomia, termo que provém do grego "Ergon" que significa "trabalho" e "nomos" que significa "leis ou normas" conforme menciona Abrahão (2009, p. 18). A ergonomia é uma disciplina que busca compreender a atividade humana em seu caráter holístico agregando a esse entendimento os aspectos físicos, sociais, cognitivos organizacionais, ambientais, entre outros. Seu principal objetivo é transformar os aspetos físicos do trabalho de modo que este seja "totalmente adaptável" ao homem em suas diversas características no seu processo produtivo (ABRAHÃO, 2009, p. 18).

Almeida (2011) sugere basicamente duas vertentes de estudo para a Ergonomia: a Ergonomia anglo-saxônica ou clássica, majoritária e liderada pelos americanos e britânicos, e a Ergonomia francesa ou contemporânea, praticada, sobretudo, nos países de língua francesa. As pesquisas ergonômicas na linha contemporânea geraram vários desdobramentos para os estudos da ação prática do trabalho, demandando assim, metodologias diferenciadas ao entendimento do mesmo.

De acordo com Belliès (2013, tradução nossa) no período entre os anos 1980-1990 novas questões vão emergindo e lançando fundamentos para a consolidação da perspectiva de análise do trabalho que é denominada de Ergologia, objeto deste trabalho. Os problemas recorrentes das crises do trabalho e emprego em função da oposição das forças sociais aos modelos de trabalho tayloristas e fordistas, o desemprego, a reestruturação das fábricas e a deslocalização do emprego vão viabilizar o nascimento dessa corrente de pesquisa.

Em 1980, uma das principais empresas de reparação naval de Marseille, Terrin, fechou suas portas e a Universidade de Provence é mobilizada para participar na recolocação de 6.000 trabalhadores da empresa. Assim os pesquisadores, Yves Schwartz (filósofo), Bernard Vuillon (sociólogo) e Daniel Faïta (linguista) e mais quinze trabalhadores assalariados, decidem trabalhar juntos no âmbito da formação 
profissional. Schwartz (2000) propõe um estágio de formação contínua em que fossem oportunizados o diálogo e a construção de saberes de forma coletiva e a capacitação dos sujeitos envolvidos.

Esse estágio com 160 horas na Université d'Aix-Marseille em Provence, viabilizou a criação de um diploma universitário (DU) primeiramente para assalariados e, posteriormente, aberto a universitários e outros profissionais. Essa formação foi composta por pesquisadores da Medicina, Ergonomia, Psicologia, Linguística e trabalhadores das indústrias.

Entre 1983 e 1984 Schwartz, Vuillon e Faïta fundaram então o dispositivo Análise Pluridisciplinar de Situações de Trabalho (APST) cujo projeto era pensar a transformação do trabalho e da atividade de trabalho com todos os protagonistas destas atividades (VIEIRA JÚNIOR; SANTOS, 2012).

\begin{abstract}
Eles tinham como desafio pensar as mutações do trabalho que traziam fortes interrogações sobre como preparar as jovens gerações para enfrentar as mudanças que atravessariam todos os aspectos da vida econômica e social, e notadamente aquelas concernentes às atividades de trabalho (APST, I99I). Isto implicaria responder simultaneamente outra questão inevitável: que meios têm os universitários eles mesmos para enfrentar tais novas interrogações? (APST, 1991). $\mathrm{Na}$ base desse desconforto estariam relações - muito indiretas ou concebidas de maneira estreita, formal, parcelar, instrumental - entre universitários e as atividades econômicas e sociais. Desconforto que convocava repensar as formas de colaboração entre estes atores sociais [...] (HENNINGTON; CUNHA; FISCHER, 20I I, p. 5).
\end{abstract}

A experiência destes cursos resultou na primeira publicação coletiva, L'homme producteu (1985) organizado por Faïta e Schwartz. No período desta formação na Université d'AixMarseille em Provence, foi inevitável o surgimento do confronto entre o conhecimento acadêmico e conhecimento dos trabalhadores, dos métodos com a prática.

De acordo com Schwartz (2000), no início desses estudos, a defasagem entre a esfera dos conceitos científicos e o mundo das experiências provocou certo 'desconforto intelectual', que foi minimizado pelos ganhos advindos da interação entre os conhecimentos dos dois grupos e pelo desejo de transformação da realidade dos trabalhadores. O hiato existente entre essas duas esferas começava, assim, a encurtar-se, pela socialização das experiências e debates em que todos os atores eram protagonistas (VIEIRA JÚNIOR; SANTOS, 2012, p. 88).

Deste modo Schwartz (2000) identifica que o desconforto intelectual é gerado justamente no processo de renormalização que a atividade de trabalho produz e isso tem sempre a tendência a invalidar, em parte, os saberes disciplinares, que, por conseguinte, tendem a neutralizar a história atual, local, dos homens e das atividades. A partir de então se pôde pensar que havia uma convergência de conhecimentos no modo de questionamentos, que não era pautado na neutralidade (BELLIÈS, 2013, tradução nossa).

Segundo Vatin (2006, tradução nossa), o termo Ergologia foi empregado na literatura mais recente a partir do filósofo Gilles-Gaston Granger que em 1968 avança na ideia de uma "Ergologia transcendental" para pensar o conhecimento do trabalho. De acordo com o sociólogo, essa ideia foi uma das inspirações do também filósofo Yves Schwartz para a ampliação de uma "filosofia do trabalho engajada na ação ergonômica". O termo emerge pela primeira vez no contexto contemporâneo na obra coletiva Reconnaissances du travail: pour une approche ergologique, organizada por Schwartz e publicada em 1997 (BRITO, 2006).

Nesta conjuntura, Schwartz idealiza a Ergologia, um método para compreensão do trabalho como uma construção de vida, utilizando os conhecimentos de várias outras ciências para conjuntamente analisá-lo.

Os saberes dos protagonistas se distribuem diferentemente, de maneira não linear, não disciplinar e estão ancorados nas histórias e situações concretas. Por um lado, há uma tendência a fabricar saberes que se tornam modelos alheios ao tempo, e é assim que o conceito funciona. Por outro lado, uma tendência ligada ao retrabalho da experiência e à (micro) fabricação de histórias. Podemos avaliar, então, a extrema dificuldade deste encontro, 
notadamente aquela de traduzir em palavras a experiência. (SCHWARTZ, 2000 , p. 43).

Diante disso, Schwartz propõe uma investigação mais aprofundada sobre o trabalho, ampliando a participação de interlocutores mais próximos aos novos modelos profissionais oriundos da pós-Era Industrial: desempregados, agentes de serviços, funcionários especializados, consultores, profissionais de diversos ramos públicos e privados.

O objetivo dos estudos ergológicos é conhecer melhor a ação laboriosa em sua dimensão complexa e desvelar em que condições esta atividade se realiza, isto é "[...] A Ergologia consiste num estudo de toda a atividade humana e, mas notadamente, a atividade humana de trabalho [...]" (TRINQUET, 2010, p. 95). Enquanto a Ergonomia da Atividade configurada na Análise Ergonômica do Trabalho (AET) busca compreender a adequação do trabalhador ao seu ambiente em toda a sua estrutura física, a Ergologia busca analisar a atividade de trabalho e como os trabalhadores utilizam as estratégias cognitivas para se portar neste ambiente (ABRAHÃO, 2009). Sendo a Ergologia uma disciplina do pensamento, aprendemos com o outro e emprestamos nosso saber para a construção do saber do outro.

A partir da década de 1990 a Ergologia vai se fortalecendo como ciência em suas questões epistemológicas e no desenvolvimento conceitual como jovem disciplina. Segundo Belliès (2013, tradução nossa) as questões relativas às prescrições teóricas em confronto com a prática e suas distinções trouxeram luz a noção de atividade humana de trabalho e a necessidade incondicional de entender a "vida laboriosa" microscopicamente colocada. As mudanças epistemológicas levaram a ruptura com a AET nos seguintes aspectos: 1. As questões agora estavam relacionadas às descobertas do trabalho real, um olhar de mudança radical no trabalho, em relação à representação que tinha até então; 2. Essa análise de trabalho apontou os limites do método experimental que mostrava ao pesquisador apenas parte do que acontecia no campo e não a essência de problemas concretos e reais; 3 . Mostrava ainda a questão multidisciplinar e a articulação entre o campo do laboral e o da teoria. Para a conjuntura social, política e científica daquele período a multidisciplinariedade constituía-se, de fato, uma postura inovadora; e, 4. A construção de conhecimento a partir de problemas concretos e reais, e da análise de dados empíricos e dos fatos há muito observados para construir hipóteses científicas colocava os trabalhadores como protagonistas do próprio fazer, como alguém que sabe sobre o seu trabalho e passa de objeto de pesquisa a ator de seu próprio conhecimento laboral com poder de ação sobre ele (BELLIĖS, 2013, p.141-144, tradução nossa).

Schwartz (2000) propôs o Dispositivo Dinâmico a Três Polos (DD3P) como um instrumento que permite entender os processos de (re) normalizações surgidos da atividade de trabalho e promover o diálogo equânime entre o coletivo (trabalhadores e docentes-pequisadores). Mas o que é o polo? Conforme Trinquet (2010, p. 103):

Em uma primeira definição, o termo 'polo' consiste em um lugar virtual onde se agregam, sintetizam-se e exprimem-se objetivos, competências, saberes e conhecimentos, interesses, etc., mais ou menos comuns, da realidade coletiva. Cada polo constitui, portanto, um grupo de pressão que busca conhecer e reconhecer o seu ponto de vista, seus interesses, suas concepções, junto aos outros polos que têm origem e concepções diferentes, porém, complementares. Do ponto de vista ergológico, esse é o único meio de dispor de uma visão, a mais larga possível, da situação em questão. Porém, é preciso enfatizar que não há, em um polo, indivíduos bem definidos. Trata-se de uma entidade de ideias, de conceitos, de interesses, etc., e cada ator pode, perfeitamente, intervir em diversos polos.

Para Schwartz (2007), polo é um território, não é um lugar segmentado, nem muito menos delimitado, mas um lugar em que uma série de situações intermediárias ocorrem. O DD3P é o trabalho cooperativo de formação e articulação dos polos e para que ele ocorra são necessários três elementos: primeiro, os saberes e conceitos, são as normas antecedentes a ação de trabalhar; segundo, os saberes acadêmicos e saberes da atividade, que estão no regime da "dupla 
antecipação";2 e por último a geração de um novo saber oriundo da recriação das normas num processo de intervenção do indivíduo no trabalho (SCHWARTZ; DURRIVE, 2007).

Os três polos são esquematizados da seguinte forma: o polo dos conceitos, que permite reunir materiais para produzir conhecimento, por exemplo, sobre a distinção entre atividade prescrita e real, sobre a noção de mercado, sobre o corpo humano, sobre as práticas linguísticas, sobre a comunicação e as dificuldades de traduzir em palavras, o que não podemos evitar no curso das atividades. Este é um polo técnico, onde os conhecimentos produzidos pelas disciplinas estão estocados. Trinquet (2010) também caracteriza este primeiro polo de "saberes constituídos", formalizados através das disciplinas acadêmicas e/ou profissionais, exteriores ao indivíduo e anteriores a situação de trabalho. Aqui também são elaboradas as normas no trabalho prescrito e, portanto, são "saberes desinvestidos" à atividade de trabalho. Esse saber é genérico e construído fora da atividade, sozinho não é capaz de explicar o que acontece no ambiente de laboral e por esta razão é desinvestido e desaderente à atividade de trabalho. O saber desinvestido ou constituído é aquele formalizado através do ensino formal, dos livros, dos softwares, das normas técnicas, dos programas de ensino, entre outros (TRINQUET, 2010).

O segundo polo, das forças de convocação e de reconvocação, refere-se aos saberes gerados nas atividades, cujos portadores têm necessidade de materiais que viabilizem a valorização dos seus saberes específicos e a transformação da sua situação de trabalho. Neste polo ocorre a (re) criação dos saberes acumulados na execução da atividade, é onde ocorre a microgestão dos saberes em sua aplicação prática. Como assevera Schwartz (2000, p. 44), “[...] as descrições econômicas, modelos de gestão, categorizações sociais são encontradas sem cessar em seus meios de trabalho e é preciso tratá-los e, novamente, (re) tratá-los". Trinquet (2010) considera que este é o polo "aderente" à atividade de trabalho, pois é a experiência do intelecto do indivíduo produzida

2 Schwartz e Durrive, (2007) entendem que o saber acadêmico, adquirido, codificado e estocado, durante o processo formativo, representam a "primeira antecipação" na execução de uma atividade ou de situações do cotidiano, ao mesmo tempo, quando a atividade é confrontada com esse saber acadêmico ocorre a "segunda antecipação" que diz respeito a recriação parcial das normas dadas a priori. em tempo real e por esta razão ele chama de "saber investido".

O terceiro polo, das exigências éticas e epistemológicas, é gerado a partir do encontro fecundo ente o primeiro e segundo polos. É onde ocorre o reconhecimento do outro em seus valores, o que faz e porque faz daquela maneira sua atividade de trabalho. Trinquet (2010) caracteriza este polo como o das 'exigências ergológicas' e nele são viabilizados os debates entre os dois polos anteriores. É o lócus do diálogo para buscar soluções e onde ocorrem os "processos socráticos de duplo sentido". ${ }^{3}$ Este polo se

[...] articula sobre uma determinada filosofia da humanidade, uma maneira de ver o outro como seu semelhante. Isto quer dizer que vemos o outro como alguém com quem vamos aprender coisas sobre o que ele faz, como alguém de quem não pressupomos saber, e porque faz, quais são seus valores e como eles têm sido '(re) tratados' (SCHWARTZ, 2000, p. 44).

Os saberes investidos e os saberes constituídos são complementares e indispensáveis na compreensão das situações de trabalho. Sobre o DD3P, Schwartz (2000) diz ainda que ele gera ao mesmo tempo efeitos sobre a produção de conhecimento e sobre a gestão social das situações de trabalho, pois há efeitos recíprocos entre o campo científico e o campo da gestão do trabalho. Por este motivo o autor afirma que o DD3P está situado na formação pois, ao mesmo tempo, que busca dominar os saberes que o partícipe vai compartilhar envolve também o reconhecimento do saber do outro, havendo a disponibilidade para aprender com ele (SCHWARTZ; DURRIVE, 2007).

Isto porque, no quadro atual, a produção de saberes, de conceitos, de descrições no campo do conhecimento tem um impacto, seja pelo viés do ensino ou por quaisquer outros político-culturais, sobre a maneira pela qual vamos gerir, dirigir. $E$ inversamente, o que se passa no quadro

3 Não há somente um Sócrates (aquele que sabe) mas no diálogo os que executam (aqueles que buscam saber) as atividades de trabalho colocam questões à Sócrates, desta forma se dá o duplo sentido para a busca das respostas apropriadas ao entendimento da atividade (TRINQUET, 20I0, p. 99).

Inf. \& Soc.:Est., João Pessoa, v.27, n.2, p. 07-17, maio/ago. 2017 
atual das gestões sociais tem um impacto sobre os saberes disciplinares. Este dispositivo a três polos, destinado a ampliar e transformar estes efeitos recíprocos deve ser acionado em todos os níveis, na universidade, mas, também, nos locais de gestão e de transformação de atividades de trabalho (SCHWARTZ, 2000, p. 45, grifos nossos).

O DD3P tem a função de produzir um aprofundamento comum entre diferentes parceiros no processo de construção de saberes e um lugar de encontro que objetiva reflexões coletivas. Cada disciplina é um reservatório de competências que ao serem discutidas no coletivo tendem a se recompor e se (re) trabalhar em si mesmas (SCHWARTZ; DURRIVE, 2007). O trabalho ao ser colocado em análise pode contribuir para mudanças julgadas necessárias nos processos de formação e atuação acadêmico-científica.

Nesta dinâmica de três polos surge ainda o que Schwartz (2000, p. 44) denomina desconforto intelectual que "[...] consiste em admitir que generalidades e modelizações devem ser sempre reapreciadas. Esta disposição não se ensina, mas se empresta, no sentido de que nos impregnamos no contato recíproco com aqueles que estão no outro polo".

Colocar em prática a tripla polaridade possibilita a criação de um caminho para ampliar o conhecimento e consideração dos semelhantes no processo de trabalho, reconhecendo-se no outro e deixando-se fazer conhecido. No âmbito da Ergologia o DD3P para efeitos desta pesquisa foi operacionalizado através do Grupo de Encontro de Trabalho (GRT). ${ }^{4}$

\section{I Constituição do grupo de encontro de trabalho (GRT)}

$\mathrm{Na}$ pesquisa realizada com o objetivo de colocar em análise a atividade de gestão da informação o DD3P foi aplicado por meio do GRT, uma vez que esse propicia produzir respostas coletivas para um problema comum aos indivíduos e favorecem o que Schwartz (2011) denomina de ergoengajamento, ou seja, o entendimento da atividade em suas múltiplas direções, sem manipulação ideológica por um dos atores e sem constrangimentos.

$4 \quad$ Do original Groupe de Rencontre du Travail (GRT).
O ergoengajamento implica em relações cooperativas entre os protagonistas da atividade e os diversos grupos sociais a respeito dos seus posicionamentos dialéticos entre as normas antecedentes e o mundo das resingularizações e renormatizações da atividade.

A adoção do método ergológico implica na constituição do GRT que é um grupo de encontro onde os trabalhadores (técnicos, profissionais, professores, alunos) colocam em debate sua atividade de trabalho, buscando dinamizar o entendimento da mesma e para tanto acaba-se por colocar uma dialética entre a apropriação da atividade - que está relacionada a familiarização conceitual do trabalhador com sua atividade e a confrontação das formas "protocolarizadas da experiência industriosa" e a gestão que este trabalhador faz desse "encontros"; e a instrução da atividade - que é o ato de colocar em palavras essas experiência industriosa desdobrando habilidades, sinergias, lacunas ou inadequações das normas antecedentes (SCHWARTZ, 2011).

O GRT não é apenas um grupo de discussão, mas um grupo de ação, que tem como finalidades facilitar a produção de saberes e de ações e levar os trabalhadores a adquirirem um novo saber sobre a sua própria atividade e, que pode levá-los a agirem com segurança (TRINQUET, 2010).

\begin{abstract}
Um GRT pode ser constituído para responder a [...] os problemas encontrados no âmbito de uma empresa e/ou de uma coletividade, tais como: problemas de pesquisa e/ou de estudos, de formação, de gestão, de prevenção de riscos do trabalho, de busca de eficiência/eficácia (eficácia é definida como eficiência em médio prazo), melhoria das condições de trabalho, etc. (TRINQUET, 2010, p. 106).
\end{abstract}

Enfim, cada GRT é uma experiência singular de construção de saber. Para explorar essa característica, neste estudo, buscamos intercambiar as experiências-profissionais com os conteúdos formativos sobre GI levando em consideração os três princípios fundamentais da Ergologia apontados por Trinquet (2010, p. 107-108):

I. É preciso colocar no centro de nossas preocupações a atividade real do trabalho e não somente a atividade prescrita [...] 2. É preciso 
colocar em prática uma estrutura que favoreça a expressão e a produção de conhecimentos novos [...] 3. Terceiro e último princípio fundamental: É preciso ir, se possível, ao campo, aos locais de trabalho [...].

No que tange à pesquisa de campo não foi possível ir a cada unidade de informação conforme recomenda Trinquet ao mencionar os três princípios que ele considera fundamentais na Ergologia. Esse impedimento ocorreu devido à diversidade e às especificidades das atividades e situações de trabalho que demandariam um tempo maior para inserção da pesquisadora em cada uma das instituições onde os participantes da pesquisa atuam. Daí importância do GRT para viabilizar aos trabalhadores colocarem em análise a própria atividade de trabalho, expondo suas questões e compartilhando conhecimentos. Mas como foi constituído o Grupo no percurso?

Primeiramente, foi realizado um mapeamento dos discentes do universo do curso de Biblioteconomia que já haviam cursado as disciplinas de Gerência de Recursos Informacionais (GRI), Organização e Administração de Bibliotecas (OAB) I e II e Organização e Métodos (O\&M), geralmente estes alunos estão localizados entre o sétimo e oitavo períodos e já possuem uma percepção holística da formação em Biblioteconomia e alguma vivência com o mundo de trabalho do bibliotecário. O grupo também foi composto por docentes que ministraram ou ministram as disciplinas de gestão para o curso de Biblioteconomia e são oriundos dos departamentos de Administração, Arquivologia e Biblioteconomia da UFES. Além desses atores o GRT também foi composto por bibliotecários-gestores de unidades de informação que atuam em instituições públicas e privadas situadas nos municípios de Cariacica, Serra, Vila Velha e Vitória (Grande Vitória), quais sejam: bibliotecas públicas municipais localizadas em Cariacica, Serra, Vila Velha e Vitória; nas principais empresas de telecomunicações que possuem centros de documentação gerenciados por bibliotecários; principais indústrias atuantes na Grande Vitória que possuem bibliotecas ou centros de documentação nos seguimentos siderúrgicos, mineração, petróleo e gás e alimentícia. Ainda foram convidados os bibliotecários gestores da Biblioteca Central da Ufes e das bibliotecas setoriais que compõem o Sistema Integrado de Bibliotecas (SIB) da Universidade.
Após esse procedimento foram convidados por e-mail e por telefone no mês de maio de 2015 quarenta e cinco (45) indivíduos entre bibliotecários, docentes e discentes para comporem o GRT. Do total de 45 profissionais 14 deles disponibilizaram-se a protagonizar a análise da atividade de trabalho. Verificamos que o grupo em sua totalidade foi composto pelo gênero feminino, apesar de terem sido convidados vários gestores do gênero masculino.

\section{I.I Modo de funcionamento do GRT}

No primeiro encontro do grupo procedeuse uma breve apresentação dos 14 participantes que se dispuseram a discutir suas atividades de trabalho. Expusemos o problema e os objetivos da pesquisa bem como a metodologia que seria aplicada. Também acordamos coletivamente quais seriam os dispositivos de discussão e elaboramos a agenda dos próximos encontros. A partir do diálogo estabelecido neste momento inicial foi possível escolher os textos que subsidiaram as discussões do segundo encontro. Importante destacar que todos os encontros do GRT foram gravados em áudio e vídeo e posteriormente foram transcritos para a execução das análises das discussões.

De acordo com as diretrizes definidas pelo método ergológico, os elementos disparadores das discussões foram a matriz curricular do Curso de Biblioteconomia versão 2007/2 e os programas das disciplinas de OAB I e II, GRI e O\&M e dois textos, quais sejam: Souto (2014) primeiro capítulo - "atuação do bibliotecário em processos não tradicionais" e Vieira (2014) capítulo 20 - "administração de bibliotecas/unidades de informação". Ambos os autores contextualizam a GI e suas atividades abordando de modo holístico as atividades do bibliotecário gestor, citando abordagens contemporâneas de organizações brasileiras, contemplando inclusive, as atividades de profissionais que participaram neste grupo.

\section{CONSIDERAÇÕES FINAIS}

Ao colocarmos em análise coletiva a atividade de Gestão da Informação pelos participantes do GRT percebemos que promover a análise coletiva de uma atividade laboral não é uma tarefa simples tampouco os processos 
envolvidos nela são de fácil externalização pelos sujeitos. Percebemos certa confusão conceitual das participantes no entendimento das prescrições acadêmicas para a atividade em análise. Embora tenham lido previamente os textos condutores das discussões, as participantes quando confrontadas com os mesmos nos pareceu que efetivamente não articularam o conteúdo dos textos com o que acontece em sua prática nas instituições onde atuam.

A tendência acadêmica em disciplinar os saberes muitas vezes desconecta o mundo do trabalho e evidencia o distanciamento entre a este e a academia conforme afirma Trinquet (2010), o que foi confirmado no estudo.

Como um fator positivo assinalamos a disponibilidade das profissionais na participação do GRT de modo ativo, mesmo o grupo se reunindo às sextas-feiras, em período inclusive de recesso acadêmico e horários coincidentes com seus horários de trabalho. Todas se interessaram pelos debates e reflexões, que para além da atividade laboral em análise estenderam-se para uma análise da própria profissão do bibliotecário. O grupo demonstrou grande necessidade em discutir suas próprias questões de trabalho e vários casos e situações-problema emergiram dessas discussões.

No último encontro o grupo avaliou o GRT e para nossa surpresa, a totalidade do das participantes disse já haver aplicado na prática elementos que emergiram dos debates no grupo. A docente que participou ativamente dos encontros disse que levou muitos exemplos procedentes do GRT para a sala de aula e afirmou que havia feito o planejamento da disciplina para o semestre vindouro, inclusive, adotando como estratégia a vinda de gestores de informação para conversarem com seus alunos a respeito da gestão e assim aprimorar a aprendizagem, uma vez que "[...] os alunos acham o conteúdo muito utópico. Eles precisam ver que funciona na prática [...]". Ela ainda afirmou "[...] que o grupo foi fantástico, pois contribuiu para entender melhor como os conteúdos que trabalha em sala de aula são aplicados pelos profissionais no mundo do trabalho". Esse fato evidencia a perspectiva formativa do GRT enfatizada por Trinquet (2010), Schwartz e Durrive (2007) e por Schwartz (2011) sob dois pontos de vista: como grupo de apropriação (familiarização conceitual com a atividade, confrontação com as normas protocolizadas da experiência e a gestão dos encontros de encontros) e instrução (onde se expõe a experiência desdobrando-a sinergicamente com o outro). As participantes do GRT demonstraram grande interesse pelas experiências do outro, conhecer, ouvir e aprender com o processo de trabalho do colega. Talvez pela pouca ou quase nenhuma aproximação com outros bibliotecáriosgestores, pela própria característica do mundo de trabalho que as mantêm distanciadas (geralmente há apenas um bibliotecário em cada UI) salvo raras exceções em que o profissional trabalha em equipes de informação (Arquivistas, Bibliotecários, Historiadores, entre outros). $\mathrm{O}$ grupo, na percepção das participantes, também, fortaleceu convicções em relação à formação discente. Além disso, as gestoras destacaram que os encontros de trabalho possibilitaram conhecer e se aproximar dos outros colegas com outras realidades de trabalho e saber o que o outro está fazendo.

A formação continuada, na perspectiva em que hoje é realizada nas instituições formadoras é limitada tendo em vista que fornecem apenas os conceitos para a execução da atividade de GI, ou seja, o "saber constituído". A luz da Ergologia, a formação continuada pode ser ampliada partindo da perspectiva do que é vivido em serviço, o que viabilizaria a constituição de novos saberes e de uma apropriação mais aprofundada dos conteúdos prescritivos. Dar voz aos atores da atividade viabiliza a construção dialógica da formação profissional e contribui na construção coletiva de novos saberes para a prática profissional através do DD3P. Nesse sentido, o GRT foi uma ferramenta potente para a análise da atividade de GI, pois contribuiu para a aproximação do "polo dos conceitos" com o "polo dos saberem investidos" gerando o terceiro, que é o "polo das exigências ergológicas" onde são de fato constituídos os novos saberes da atividade de GI. Percebemos o quanto o diálogo foi necessário para compreendermos a aplicação dos conteúdos ministrados nas aulas de gestão, da utilidade deles e dos limites na execução da atividade.

Os limites da aplicação do método foram percebidos nas discussões dos encontros que mesmo com todo planejamento elaborado pela pesquisadora sempre outras questões emergiam e entravam no debate. Isso nos remete ao que Schwartz diz sobre a construção holística da atividade de trabalho onde está envolvida a vida laboral e o sujeito enquanto ser constituído por 
vivências não apenas laborais. O que colocamos no grupo como discussão muitas vezes fugiu a atividade restrita da gestão. Porém, o que mais chamou a atenção foi que as participantes desejavam muito que o outro conhecesse o que e como executam suas atividades, os meandros desse fazer, as dificuldades e a percepção de que o outro também possui questões semelhantes que se intercambiam e as sintoniza.

Apesar de tentar moldar as discussões aos objetivos desta pesquisa, apreendemos que há muita coisa além das palavras, assuntos não verbalizados, idiossincrasias na ação de trabalho de cada uma delas. Nestas folhas foi difícil descrever com precisão toda a riqueza do que foi debatido nos encontros do GRT pelas participantes. Narrar os olhares vívidos ao ouvir experiências que funcionam de fato e perceber que as dramáticas, apesar de vividas por algumas, ao serem compartilhadas no Grupo, é como se fossem sentidas por todas, isso nos impressionou!

Deste modo, torna-se imperativo ampliar a construção da reflexão dicotômica entre academia e mundo do trabalho, viabilizando uma aproximação real, um interesse autêntico para que juntos possamos contribuir para a formação de um profissional gestor mais próximo à realidade. Humano e técnico, sensível e assertivo. Submeter à discussão coletiva as vivências do trabalho e as inquietações dos trabalhadores em relação a sua atividade é uma importante ferramenta para o fortalecimento dos profissionais e das profissões. Esses momentos formativos coletivos dinamizam o entendimento da atividade em suas múltiplas direções, tanto formativas na academia, instrucionais normativas no mercado e experienciais na ação do trabalhador. Entendemos assim que este estudo avançou no sentido de propiciar um outro olhar sobre a formação curricular e o que ocorre de fato na atuação profissional e em uma outra possibilidade de aproximação entre a formação e a prática. Os encontros do grupo viabilizam o que Schwartz (2011) denomina de ergoengajamento ${ }^{5}$ e o fortalecimento desses encontros de trabalho gera uma nova cooperação, tanto na construção curricular mais próxima a realidade profissional vivida, quanto ao identificar no trabalhador um elemento importante para essa construção.

Tal contribuição para a área de Ciência da Informação pode ser condição transformadora de outras realidades laborais dos profissionais de informação e de uma formação mais ajustada com as realidades dos trabalhadores. Entendemos que não há formação curricular acabada em si mesma, nem mesmo gestores completos, mas a gestão se dá num ato de construção diária a partir dos contextos colocados no trabalho real e no diálogo com as prescrições da atividade.

Como encaminhamentos registramos como condição sine qua non a ampliação do debate de um modo mais sistemático e contínuo, utilizando para isso a constituição de grupo permanente de análise do trabalho do bibliotecário-gestor, para que não ocorra o distanciamento da produção coletiva sobre o entendimento dessa atividade. Por ser assim, propõe-se a constituição de um espaço permanente de diálogo para viabilizar a produção coletiva de conhecimentos sobre a atividade de GI, buscando não hierarquizar esses conhecimentos, mas colocando os saberes acadêmicos e os saberes da experiência no mesmo nível de importância na formação dos bibliotecários.

5 Ergoengajamento pressupõe relações entre os protagonistas da atividade, entre os grupos sociais que criam posturas de posicionamento dialético, entre normas antecedentes e o mundo das (re)normatizações e isso gera novas formas de cooperação (SCHWARTZ, 20I I). 
Artigo recebido em I0/03/20I6 e aceito para publicação em 03/04/20I7

\section{THE ERGOLOGY AS APORTE THEORETICAL - METHODOLOGICAL ANALYSIS FOR COLLECTIVE WORK OF THE LIBRARIAN}

ABSTRACT Presents Ergology as theoretical and methodological support, idealized by Yves Schwartz, to enable the collective analysis of the librarian work from a research that aimed to put in question the information management activity by librarians-managers. Discusses the Ergology as a powerful theoretical approach to collective analysis of working eliminating the hierarchy of knowledge between workers and researchers. Highlights the ergologic method as relevant device to trigger the analysis of labor activities by the workers themselves. Socializes the ergologic method since the dialogical process between the same as librarians, students and library science teachers about information management activity. It is concluded that the use of that method for the analysis of work entices workers to a reflexivity about their work, resulting in the expansion of the power to act in the case of librarians who, historically, have been asked to put in question: What are you doing? How do? Why do? To do?

Keywords: $\quad$ Librarian work. Ergology. Analysis of work activity. Ergology - analyze collective work.

\section{REFERÊNCIAS}

ABRAHÃO, Júlia et al. Introdução à ergonomia: da prática à teoria. São Paulo: Blucher, 2009.

ALMEIDA, Rodrigo Gomes de. A ergonomia sob a ótica anglo-saxônica e a ótica francesa. Vértices, Campos dos Goytacazes, v. 3, n. 1, p. 111-121, jan./abr. 2011.

BELLIÈS, Laurence. Ergonomie et ergologie: les apports reciproques. Ergologia, n. 9, maio 2013, p. 133-163. Disponível em: <http:/ / www.ergologia. org/uploads/1/1/4/6/11469955/9._p._2_bellis. pdf>. Acesso em: 14 nov. 2015.

BRITO, José Eustáquio. Reflexões epistemológicas sobre a ergologia. Núcleo de Estudos sobre Trabalho e Educação - FaE/UFMG. In: REUNIÃO ANUAL DA ASSOCIAÇÃO NACIONAL DE PÓS-GRADUAÇÃO E PESQUISA EM EDUCAÇÃO, 29., 2006, Belo Horizonte. Anais... Belo Horizonte, 2006.

CASTELLS, Manuel; CARDOSO, Gustavo (Org.). A sociedade em rede: do conhecimento à ação política. Belém: Imprensa Nacional, 2005.

CLOT, Yves. A psicologia do trabalho na França e a perspectiva da clínica da atividade. Fractal, Rio de Janeiro, v. 22, n.1, p. 207-234, jan/abr. 2010.
HENNINGTON, Élida Azevedo; CUNHA, Daisy Moreira; FISCHER, Maria Clara Bueno. Trabalho, educação, saúde e outros possíveis: diálogos na perspectiva ergológica. Revista Trabalho Educação e Saúde, Rio de Janeiro, v. 9, supl. 1, p. 5-18, 2011. Disponível em: < http://www.scielo. br/pdf/tes/v9s1/01.pdf> Acesso em: 14 nov. 2015.

SAMPAIO, Jorge. A Sociedade em rede e a economia do conhecimento: Portugal numa perspectiva global. In: CASTELLS, Manuel; CARDOSO, Gustavo (Org.). A sociedade em rede: do conhecimento à ação política. Belém: Imprensa Nacional, 2005. p. 419-426.

SCHWARTZ, Yves. A comunidade científica ampliada e o regime de produção de saberes. Trabalho e Educação, Belo Horizonte, n. 7, p. 3846, jul./dez. 2000. Disponível em: < http://www. portal.fae.ufmg.br/seer/index.php/trabedu / article/viewFile/1681/1274> Acesso em: 15 jul. 2015.

SCHWARTZ, Yves; DURRIVE, Louis (Org.). Trabalho e Ergologia: conversas sobre a atividade humana. Niterói: EdUFF, 2007.

SOUTO, Leonardo Fernandes. Atuação do bibliotecário em processos não tradicionais. In: (Org.). Gestão da informação e 
do conhecimento: práticas e reflexões. Rio de Janeiro: Interciência, 2014. p. 1-26.

TRINQUET, Pierre. Trabalho e educação: o método ergológico. Revista HISTEDBR Online, Campinas, número especial, p. 93-113, ago. 2010. Disponível em: <http://www.histedbr. fe.unicamp.br/revista/edicoes/38e/art07_38e. pdf>. Acesso em: 10 jul. 2014.

VATIN, François. Origines historiques de l'ergonomie et de l'ergologie. Aix em Provence: Marseille Université/Institut d'Ergologie, 2006.
Disponível em: < http://www.up.univ-mrs.fr/ ergolog/html/historique.php>. Acesso em: 02 de nov. 2015.

VIEIRA, Ronaldo. Introdução à teoria geral da biblioteconomia. Rio de janeiro: Interciência, 2014.

VIEIRA JÚNIOR, Paulo Roberto; SANTOS, Eloisa Helena. A gênese da perspectiva ergológica: cenários de construção e conceitos derivados. Trabalho \& Educação, Belo Horizonte, v. 21, n.1, p. 83-100, jan./abr.2012. 